\title{
Compassionate use of remdesivir in pregnancy: a case series
}

\author{
Jui R. Shah"1, Khushali P. Parikh', Aayushi A. Suthar², \\ Sushma R. Shah ${ }^{2}$, Supriya D. Malhotra ${ }^{1 *}$
}

\begin{abstract}
${ }^{1}$ Department of Pharmacology, ${ }^{3}$ Department of Obstetrics and Gynecology, Smt. NHL Municipal Medical College,
\end{abstract} Ahmedabad, Gujarat, India

Received: 13 August 2021

Accepted: 06 September 2021

\section{*Correspondence:}

Dr. Supriya D. Malhotra,

E-mail: supriyadmalhotra@gmail.com

Copyright: (C) the author(s), publisher and licensee Medip Academy. This is an open-access article distributed under the terms of the Creative Commons Attribution Non-Commercial License, which permits unrestricted non-commercial use, distribution, and reproduction in any medium, provided the original work is properly cited.

\begin{abstract}
Coronavirus disease 2019 (COVID-19) has resulted in an unprecedented global healthcare crisis. One special population that poses a challenge is pregnant women with COVID-19. However, there is limited data on treatment options for severe coronavirus disease in pregnancy. Remdesivir, an antiviral drug, is currently being studied as a potential treatment of COVID-19 pneumonia. Nevertheless, pregnant women are also being excluded from various clinical trials for the disease. There are some studies mentioned in the literature which have shown no adverse effects of remdesivir during pregnancy. In this study, we present four serial cases of COVID-19 in pregnant women with moderate to severe symptoms who were treated with remdesivir. All of the them showed positive fetal outcome without any birth defects or malformations. However, further studies are necessary to evaluate the biosafety and effects of remdesivir in pregnant women.
\end{abstract}

Keywords: COVID-19, Remdesivir, Pregnancy, Moderate-severe symptoms

\section{INTRODUCTION}

Severe acute respiratory syndrome Corona virus 2 (SARS$\mathrm{CoV}-2)$ infection that has caused the novel Coronavirus disease 2019 (COVID-19) has become a major health problem worldwide with thousands of mortality cases. ${ }^{1}$ Physiological and immune system alterations during pregnancy lead to increased vulnerability towards SARSCoV-2 infection, hence worsening its outcome. ${ }^{2}$ However, there is no evidence that pregnant women are more susceptible to the infection than the general population; but pregnancy-associated immunological changes could potentially make the pregnant individuals more at risk to severe COVID-19 as has been previously observed with influenza $\mathrm{A} / \mathrm{H} 1 \mathrm{~N} 1$, SARS and middle east respiratory syndrome (MERS). ${ }^{3,4}$

As a special population, managing COVID-19 in pregnant women presents as a challenge. Pregnant women all over the world have been infected by this virus with varying degrees of severity. There is still no standardized treatment in pregnant women with COVID-19, both at national and international levels. Pregnant women were often excluded from some studies to evaluate novel therapy for COVID19. However, these data are needed to determine the efficacy and safety of COVID-19 management in pregnancy. ${ }^{1,5}$

Remdesivir inhibits SARS-CoV-2 replication by inhibiting RNA-dependent RNA-polymerase. Few preliminary trials have shown the efficacy of remdesivir in shortening the duration and severity of moderate and severe COVID-19 disease in adults. Based on these results, emergency use authorization of remdesivir was granted by the United States food and drug administration and ministry of health and family welfare, India. However, pregnant women have largely been excluded from these 
clinical trials, thus making the management of severe COVID-19 in pregnancy more challenging. ${ }^{6-8}$

Here in we describe in detail about 4 cases of pregnant women with moderate to severe COVID-19 pneumonia admitted to our hospital, in whom compassionate use of remdesivir was done.

\section{CASE SERIES}

\section{Case 1}

A 29-year-old pregnant woman with previous history of one abortion and one live birth at full term by normal delivery, came with 7 months of amenorrhea (31 weeks of gestation) and had chief complains of fever, cough, weakness and body ache for 1 day was tested reverse transcriptase polymerase chain reaction (RTPCR) positive for COVID-19 and admitted to the hospital. The vitals were temperature: $100.1^{\circ} \mathrm{C}$, pulse: $110, \quad \mathrm{SpO}_{2}: 97 \%$, respiratory rate $(\mathrm{RR}): 20 / \mathrm{min}$ and blood pressure $(\mathrm{BP})$ : $124 / 84 \mathrm{mmHg}$. On hospitalization day 2 , the inflammatory markers were slightly raised, C-reactive protein (CRP): $33.54 \mathrm{mg} / \mathrm{l}(<5 \mathrm{mg} / \mathrm{l}:$ negative $)$ and D-dimer: $0.75 \mu \mathrm{g} / \mathrm{ml}$ $(<0.5 \mu \mathrm{g} / \mathrm{ml}$ : negative $)$. She was given supportive treatment for fever and after that injection Monocef ( $1 \mathrm{gm}$ IV BD) and injection dexamethasone (16 mg IV OD) were started. The D-dimer levels further increased (D-dimer: $6.96 \mu \mathrm{g} / \mathrm{ml}$ ) and on day 7 injection low molecular weight heparin (LMWH) $(0.6 \mathrm{ml}$ SC OD) was started. On hospitalization day 8 , the patient was tachypnoeic (RR: $28 / \mathrm{min}$ ) and $\mathrm{SpO}_{2}$ was $92 \%$ on room air (RA). Injection remdesivir $200 \mathrm{mg}$ IV on first day and $100 \mathrm{mg}$ IV for next 4 days was started in the view of consistent fever and extremely raised inflammatory markers (CRP: $140 \mathrm{mg} / \mathrm{l}$ and D-dimer:13.09 $\mu \mathrm{g} / \mathrm{ml})$. On hospitalization day 10 , there was feto-maternal distress due to COVID and thus an elective lower section cesarean section (LSCS) was done and the child of $1.5 \mathrm{~kg}$ was delivered. Baby tested negative for COVID-19 and was shifted to the neonatal ICU. Mother was maintaining $\mathrm{SpO}_{2}: 96 \%$ at $6 \mathrm{~L} / \mathrm{min} \mathrm{O}_{2}$. By hospitalization day 15 the markers decreased and oxygen requirement also reduced and she was maintaining $\mathrm{SpO}_{2}: 98 \%$ at $2 \mathrm{~L} / \mathrm{min} \mathrm{O}_{2}$. Finally on hospitalization day 24 , she was stable and discharged from the hospital.

\section{Case 2}

A 28-year-old pregnant woman, who is a primi gravida with 29 and 4 weeks of gestation, came with chief complains of fever, cough and breathlessness for 2 days and was diagnosed COVID-19 positive by RTPCR test. The vitals on admission were temperature: $100.1^{\circ} \mathrm{C}, \mathrm{RR}$ : 18/min, p: $100 /$ min and $\mathrm{SpO}_{2}: 90 \%$ on RA. On the next day of hospitalization, the inflammatory markers showed an evident rise (CRP:171.15 mg/l and D-dimer:1.12 $\mu \mathrm{g} / \mathrm{ml}$ ) and she was put on $4 \mathrm{~L} \mathrm{O}_{2} / \mathrm{min}$ to maintain normal oxygen saturation. In context with the raised markers and increased oxygen requirement, Injection remdesivir 200 $\mathrm{mg}$ IV on first day and $100 \mathrm{mg}$ IV for next 4 days was started. Along with that injection Monocef (1 gm IV BD), injection dexamethasone (16 mg IV OD) and LMWH (0.6 $\mathrm{ml}$ SC OD) were also started. On hospitalization day 3 , the CRP levels reduced to $50.74 \mathrm{mg} / \mathrm{l}$. Then after on hospitalization day 6 , the CRP levels drastically reduced to $3.98 \mathrm{mg} / \mathrm{l}$ and she maintained $\mathrm{SpO}_{2}$ : $97 \%$ on room air. As her condition improved, she was finally discharged from the hospital on $7^{\text {th }}$ day. After 2 months she delivered a healthy baby of $2.4 \mathrm{~kg}$ by normal delivery.

\section{Case 3}

A 28-year-old woman with 32 weeks of gestation and previous history of one live birth by cesarean section, was admitted to the hospital with chief complains of fever cough and weakness for three days. Her vitals on admission were temperature: $99.8^{\circ} \mathrm{C}$, pulse: $98 / \mathrm{min}$, RR: 18/min and $\mathrm{SpO}_{2}: 93 \%$ on room air. She was tested COVID-RTPCR positive. Laboratory reports showed raised inflammatory markers on the first day (Ddimer: $1.58 \mu \mathrm{g} / \mathrm{ml}, \mathrm{CRP}: 68 \mathrm{mg} / \mathrm{l})$. Hence, from the second day itself Injection remdesivir $200 \mathrm{mg}$ IV on first day and $100 \mathrm{mg}$ IV for next 4 days was started. For reducing the inflammation injection methylprednisolone $40 \mathrm{mg}$ IV 12 hourly was also considered. She was maintaining $94 \%$ $\mathrm{SpO}_{2}$ on $2 \mathrm{~L} / \mathrm{min} \mathrm{O}_{2}$ by nasal prongs. On hospitalization day 5 , after 4 days of remdesivir the patient was vitally stable, maintained normal oxygen on room air and inflammatory markers showed a decreasing trend. Finally, after 8 days of hospitalization the patient was discharged. Then after a month at full-term a child of $2.5 \mathrm{~kg}$ was delivered by cesarean section.

\section{Case 4}

A 36-year-old pregnant female with 30 and 2 weeks of gestation and previous history of one abortion and one live birth at full term by normal delivery. She came with chief complains of fever, weakness and breathlessness for 2 days. She was tested positive for COVID-19 by RTPCR test. The vitals on admission were temperature: $100.1^{\circ} \mathrm{C}$, pulse: 108/min, RR: 20/min and $\mathrm{SpO}_{2}$ : $92 \%$. She was suffering from gestational hypertension and had blood pressure of $160 / 100 \mathrm{mmHg}$. She was immediately put on $8 \mathrm{~L} \mathrm{O}_{2} /$ min by NRBM and was maintaining $\mathrm{SpO}_{2}$ : $96 \%$. On the next day the patient was tachypnoeic (RR:25/min), the oxygen requirement increased to $40 \mathrm{~L} \mathrm{O}_{2} / \mathrm{min}$ on $100 \%$ $\mathrm{FiO}_{2}$ by HFNC, 2D echo screening was also carried out which showed grade 2 mitral regurgitation and mild tricuspid regurgitation, mild to moderate pulmonary hypertension (PAH) and dilated right ventricle (RV). Also, the inflammatory markers showed an increase (D-dimer: $1.25 \mu \mathrm{g} / \mathrm{ml}$, CRP: $127.20 \mathrm{mg} / \mathrm{l}$, lactate dehydrogenase (LDH): $408 \mathrm{U} / \mathrm{L}$, interleukin-6 (IL-6): $75.8 \mathrm{pg} / \mathrm{ml}$ ). In the view of deteriorating condition of the patient injection remdesivir $200 \mathrm{mg}$ IV on first day and $100 \mathrm{mg}$ IV for next 4 days was considered for this patient and started immediately along with injection dexamethasone (12 mg IV BD), injection heparin (5000 IU IV BD). On hospitalization day 3 , emergency LSCS was performed 
due to feto-maternal distress as a result of COVID-19 and she gave birth to a child of $1.51 \mathrm{~kg}$, the child tested negative for COVID-19 and was shifted to the neonatalICU (NICU). The mother was put on put $50 \mathrm{~L} \mathrm{O}_{2} / \mathrm{min}$ $100 \% \mathrm{FiO}_{2}$ on bilevel positive airway pressure (BiPAP) ventilation. She was still not maintaining normal oxygen saturation and her condition kept on worsening. Hence, she was intubated and put on volume control ventilation (VCV) mode with $3 \mathrm{~L}$ on $100 \% \mathrm{FiO}_{2}$. The inflammatory markers further showed an increasing trend and her condition kept on deteriorating. On hospitalization day 5, she was tachypnoeic (RR: 27/min), tachycardic (Pulse: $150 / \mathrm{min})$, hypotensive $(98 / 50 \mathrm{mmHg})$ and she was not maintaining normal oxygen saturation. Injection noradrenaline 1 ampoule IV stat was started along with cardio pulmonary resuscitation according to advanced cardiovascular life support (ACLS) guidelines. Thus, 2 days after the emergency LSCS the patient died.

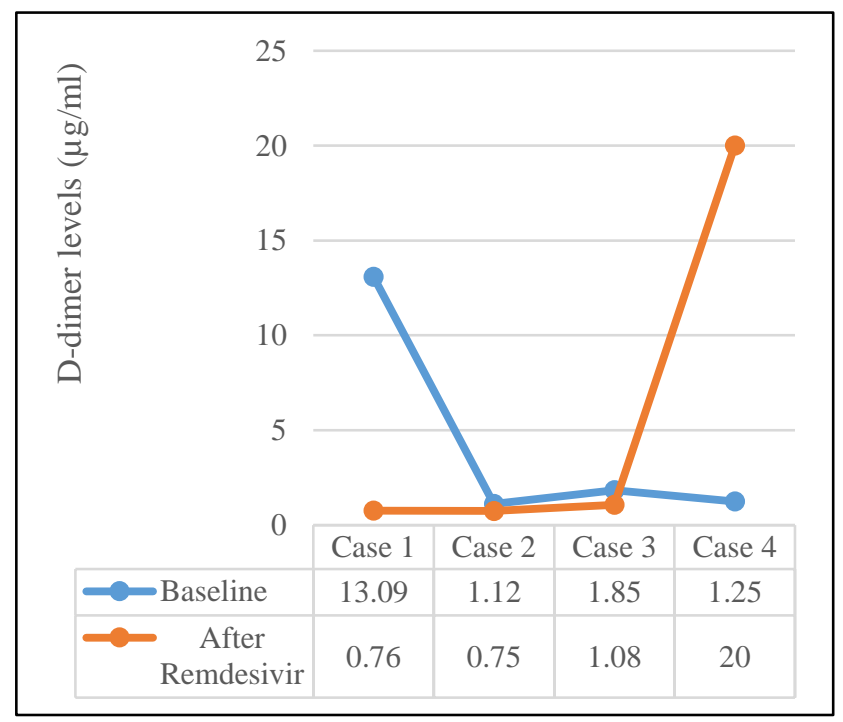

Figure 1: D dimer levels at baseline and after remdesivir.

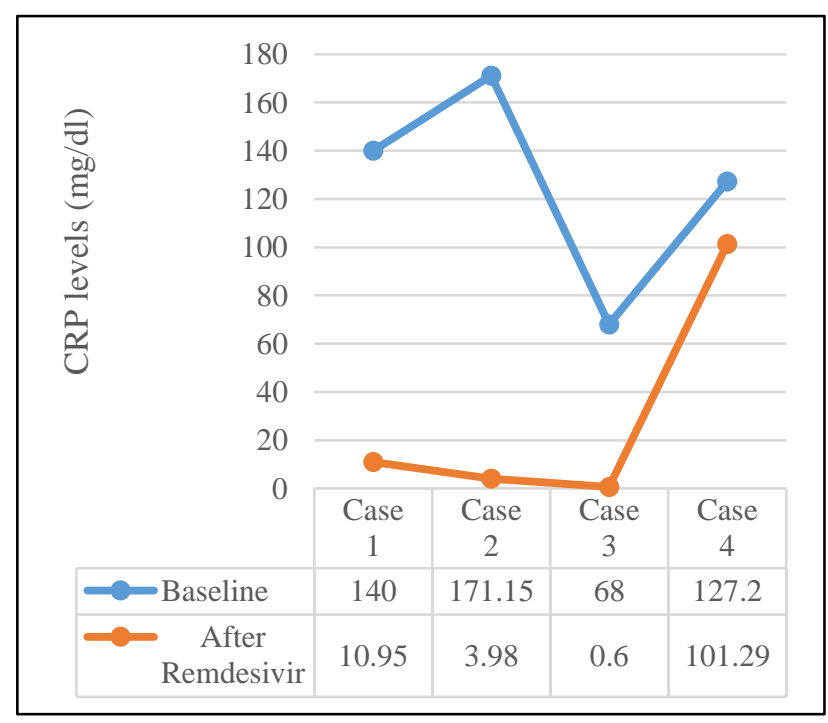

Figure 2: CRP levels at baseline and after remdesivir.

\section{DISCUSSION}

SARS-CoV-2, is a positive-sense RNA virus and the causative agent of COVID-19. Recent data have shown that pregnant women diagnosed with COVID-19 have an increased risk of ICU admission, need of mechanical ventilation, and mortality compared to non-pregnant women of the similar age group. ${ }^{8}$

Remdesivir, an inhibitor of RNA polymerase, has been used in COVID-19 treatment and is known to shorten recovery time in nonpregnant women. Several studies have shown that the use of remdesivir did not result in adverse effects for pregnant women. On the basis of a randomized control trial (RCT) performed during the Ebola epidemic, remdesivir was safe to use for pregnant women. ${ }^{1,5}$ As the COVID-19 pandemic continues and pregnant women remain at risk for adverse medical and obstetrical outcomes, having safe and effective therapies, such as remdesivir, is crucial for this population. However, contrary to this need, pregnant women have largely been left out from clinical trials during COVID-19 pandemic. ${ }^{9}$

In our cases, no adverse effect of remdesivir was observed on both the mother and fetus. In all the cases the main reason for initiating the remdesivir therapy was the marked rise in the inflammatory markers, mainly CRP and Ddimer. However, simultaneous reduction in the oxygen saturation also played a role in starting the therapy. Other drugs like injection LMWH, injection Monocef and injection dexamethasone (in cases 1 and 2) were also given in these patients. As a result of the pregnant status of women, computed tomography (CT) scans and x-rays were not performed, hence it proved to be the limitation that we could not get the CT severity score and the X-ray changes in the lungs of these patients.

In the cases 1, 2 and 3; inflammatory markers showed a remarkable decline (Figure 1 and 2) and oxygen saturation improved after introduction of remdesivir in their treatment. Also, the period of hospital stays in the patients shortened. Two patients (Case 1 and 4) delivered preterm babies by LSCS during their hospital stay; while rest of the two (case 2 and 3) delivered healthy babies at term. All four of the babies had no birth defects and they tested negative for COVID-19.

The only case (case 4) that showed a negative outcome was due to underlying co-morbidities like gestational hypertension and pulmonary arterial hypertension. The cause of death in the patient was cardiac arrest, unrelated to the remdesivir therapy.

However, there are other anti-viral drugs like oseltamivir that can also be considered in COVID-19. But its previous use in pregnancy during the novel influenza $A$ (H1N1) pandemic in 2009, showed some adverse effects on foetuses (defects in the cardiovascular, musculoskeletal and genitourinary systems), especially if it was given in the first trimester. Apart from the adverse effects the 
effectiveness of oseltamivir in reducing the severity is lower as compared to remdesivir. ${ }^{12}$

There are also some other studies listed in the literature that have shown safe use of remdesivir with positive outcomes during pregnancy. $1,5,8,10,11$

\section{CONCLUSION}

In our cases, we observed no adverse events in patients, foetuses, and also neonates. They were also unlikely to happen as remdesivir was initiated much after the period of organogenesis (i.e., first 3 months of fetal life). But further studies are still needed to evaluate the adverse events from the interactions of the medications used as a part of COVID therapy, especially in pregnant population. Although remdesivir is not approved for use in pregnancy, a global database can be generated to evaluate the outcomes of all such mothers who were given remdesivir during the peak of the COVID wave, retrospectively.

Funding: No funding sources

Conflict of interest: None declared

Ethical approval: Not required

\section{REFERENCES}

1. Igbinosa I, Miller S, Bianco K, Nelson J, Kappagodaet S, Blackburn BG et al. Use of remdesivir for pregnant patients with severe novel coronavirus disease 2019. Am J Obstet Gynecol. 2020;223:768-70.

2. Odayar J, Myer L, Malaba TR. The epidemiology and pathogenesis of SARS-CoV-2 infection in pregnancy: More questions than answers. E-Clin Med. 2020;26:100534.

3. Knight M, Bunch K, Vousden N, Morris E, Simpson $\mathrm{N}$, Gale $\mathrm{C}$ et al. Characteristics and outcomes of pregnant women admitted to hospital with confirmed SARS-CoV-2 infection in UK: national populationbased cohort study. BMJ. 2020;m2107.
4. Lampejo T. Remdesivir for the treatment of COVID19 in pregnancy. J Med Virol. 2021;93(7):4114.

5. Saroyo YB, Rumondang A, Febriana IS, Harzif AK, Irwinda R. Remdesivir Treatment for COVID-19 in Pregnant Patients with Moderate to Severe Symptoms: Serial Case Report. Infect Dis Rep. 2021;13:437-43.

6. US Food and Drug Administration. Remdesivir EUA letter of authorization. 2020. Available at: https://www.fda.gov/media/137564/download. Accessed on March 22, 2021.

7. National Clinical management protocol: COVID-19. 2020. Available at: https://www.mohfw.gov.in/pdf/UpdatedClinicalMan agementProtocolforCOVID19dated03072020.pdf. Accessed on March 22, 2021.

8. Singh V, Choudhary A. Treatment with Remdesivir in Two Pregnant Patients With COVID-19 Pneumonia. Cureus. 2020;13(5):e14986.

9. Smith DD, Pippen JL, Adesomo AA, Rood KM, Landon MB, Costantine MM. Exclusion of pregnant women from clinical trials during the coronavirus disease 2019 pandemic: a review of international registries. Am J Perinatol. 2019;37(8):792-9.

10. Dande R, Qureshi A, Persaud K, Puri C, Zulfiqar S, Awasthi S. Remdesivir in a pregnant patient with COVID-19 pneumonia. J. Community Hosp Intern Med Perspect. 2021;11:103-6.

11. Maldarelli GA, Savage M, Mazur S, Oxford-Horrey C, Salvatore M, Marks KM. Remdesivir treatment for severe COVID-19 in third-trimester pregnancy: case report and management discussion. Open Forum Infect Dis. 2020;7(9):ofaa345.

12. Donner B, Niranjan V, Hoffman G. Safety of Oseltamivir in pregnancy. Rev Preclin Clin Data Drug Saf. 2010;33:631-42.

Cite this article as: Shah JR, Parikh KP, Suthar AA, Shah SR, Malhotra SD. Compassionate use of remdesivir in pregnancy: a case series. Int J Reprod Contracept Obstet Gynecol 2021;10:3950-3. 